\title{
Cost-effectiveness analysis of medical treatment of benign prostatic hyperplasia in the Brazilian public health system
}

\author{
Luciana Ribeiro Bahia, Denizar Vianna Araujo, Camila Pepe, Michelle Trindade, Caroline Mendonça \\ Camargo, Valter Javaroni
}

State University of Rio de Janeiro, Rio de Janeiro, Brazil

\section{ABSTRACT}

Objective: To perform a cost-effectiveness analysis of medical treatment of benign prostatic hyperplasia (BPH) under Brazilian public health system perspective (Unified Health System - "Sistema Único de Saúde (SUS)").

Material and Methods: A revision of the literature of the medical treatment of BPH using alpha-blockers, 5-alpha-reductase inhibitors and combinations was carried out. A panel of specialists defined the use of public health resources during episodes of acute urinary retention (AUR), the treatment and the evolution of these patients in public hospitals. A model of economic analysis(Markov) predicted the number of episodes of AUR and surgeries (open prostatectomy and transurethral resection of the prostate) related to BPH according to stages of evolution of the disease. Brazilian currency was converted to American dollars according to the theory of Purchasing Power Parity (PPP 2010: US\$ $1=\mathrm{R} \$ 1.70$ ). Results: The use of finasteride reduced 59.6\% of AUR episodes and 57.9\% the need of surgery compared to placebo, in a period of six years and taking into account a treatment discontinuity rate of 34\%. The mean cost of treatment was R 764.11 (US\$449.78) and $\mathrm{R} \$ 579.57$ (US\$ 340.92) per patient in the finasteride and placebo groups, respectively. The incremental cost-effectiveness ratio (ICERs) was R\$ 4.130 (US\$2.429) per episode of AUR avoided and R\$ 2.735 (US\$ 1.609) per episode of surgery avoided. The comparison of finasteride + doxazosine to placebo showed a reduction of 75.7\% of AUR episodes and $66.8 \%$ of surgeries in a 4 year time horizon, with a ICERs of R $\$ 21.191$ (US\$ 12.918) per AUR episodes avoided and R $\$ 11.980$ (US\$ 7.047) per surgery avoided. In the sensitivity analysis the adhesion rate to treatment and the cost of finasteride were the main variables that influenced the results.

Conclusions: These findings suggest that the treatment of BPH with finasteride is costeffective compared to placebo in the Brazilian public health system perspective.

\section{ARTICLE INFO}

\section{Key words:}

Cost-effectiveness Analysis; Benign Prostatic Hyperplasia; Finasteride; Doxazosin

Int Braz J Urol. 2012; 38: 595-605

Submitted for publication: January 31, 2012

Accepted after revision: May 22, 2012

\section{INTRODUCTION}

Benign Prostatic Hyperplasia (BPH) is one of the most common diseases in men, being considered part of the physiological process of aging. BPH prevalence among men of 70 years old is about $40 \%$, according to population studies (1-3). However, there is a great variation of prevalence in the literature, ranging from $13 \%$ to $46 \%$, according to diagnostic criteria, region studied and age of sample (4). Regarding to BPH incidence, the data are still more scarce (5-7). A cohort study conducted in Holland showed a general incidence of 15 per 1000 men/year, with an evident correlation between incidence and age (4). BPH is a chronic and progressive condition that, if inappropriately 
treated, may progress to acute urinary retention (AUR), recurrent urinary infection, hydronephrosis and eventually renal failure. However, clinical presentation is widely variable as well as individual progression of the disease (8). While some men present lower urinary tract symptoms (LUTS) and significant reduction of quality of life, even in the absence of significant prostatic growth, others with an important prostatic growth may be asymptomatic or present mild symptoms. The presence of mild to moderate LUTS and urinary flow less than $15 \mathrm{~mL} / \mathrm{s}$ probably represent $\mathrm{BPH}$ diagnosis and treatment options should be discussed with the patient. Several options are available, from watchful waiting, medical treatment to surgery. The objective is to reduce the intensity of symptoms, normalize the dynamics of lower urinary tract and prevent eventual complications (9). Cost-effectiveness analysis of medical treatment of BPH in the public health system of Brazil (Unified Health System - "Sistema Único de Saúde - SUS") presents useful information for those involved in the development of health policies and financial resources allocation. Benign Prostatic Hyperplasia (BPH) is one of the most common diseases in men, being considered part of the physiological process of aging. BPH prevalence among men of 70 years old is about 40\%, according to population studies (1-3). However, there is a great variation of prevalence in the literature, ranging from $13 \%$ to $46 \%$, according to diagnostic criteria, region studied and age of sample (4). Regarding to BPH incidence, the data are still more scarce (5-7). A cohort study conducted in Holland showed a general incidence of 15 per 1000 men/year, with an evident correlation between incidence and age (4). BPH is a chronic and progressive condition that, if inappropriately treated, may progress to acute urinary retention (AUR), recurrent urinary infection, hydronephrosis and eventually renal failure. However, clinical presentation is widely variable as well as individual progression of the disease (8). While some men present lower urinary tract symptoms (LUTS) and significant reduction of quality of life, even in the absence of significant prostatic growth, others with an important prostatic growth may be asymptomatic or present mild symptoms. The presence of mild to moderate LUTS and urinary flow less than $15 \mathrm{~mL} / \mathrm{s}$ probably represent $\mathrm{BPH}$ diagnosis and treatment options should be discussed with the patient. Several options are available, from watchful waiting, medical treatment to surgery. The objective is to reduce the intensity of symptoms, normalize the dynamics of lower urinary tract and prevent eventual complications (9). Cost-effectiveness analysis of medical treatment of BPH in the public health system of Brazil (Unified Health System - "Sistema Único de Saúde - SUS") presents useful information for those involved in the development of health policies and financial resources allocation.

\section{MATERIALS AND METHOS}

\section{Systematic Review of Literature}

The following databases were used to find clinical randomized studies and systematic reviews: Cochrane Database of Systematic Reviews (CDSR); Cochrane Clinical Trials; Database of Abstracts of Reviews of Effectiveness (DARE); Health Technology Assessment (HTA) Database; NHS Economic Evaluations Database (NHS EED); EMBASE; LILACS; MEDLINE via Pubmed.

The following key words were used to search MEDLINE via Pubmed: $\alpha$-Blockers: \#1: "Doxazosin"[Mesh] \#2: "tamsulosin "[Substance Name] \#3: "terazosin "[Substance Name] \#4: "alfuzosin"[Substance Name]; $5 \alpha$-reductase inhibitors: \# 1: "Finasteride"[Mesh] \#2: "dutasteride "[Substance Name]; Benign Prostatic Hyperplasia: \# 1: "Prostatic Hyperplasia"[Mesh].

Data were obtained independently by two reviewers using a standardized sheet. A third reviewer solved the discrepancies between the two main reviewers.

\section{Treatment of BPH in the Brazilian Public Health System}

Due to the lack of data regarding $\mathrm{BPH}$ treatment in Brazil, a panel of specialists was conducted, in order to provide data to the economical model. The results were used in addition to the literature data and the current available consensus. The panel was constituted by 5 urologists from Rio de Janeiro City (Hospital Municipal 
Souza Aguiar and Hospital Federal de Bonsucesso) and two from São Paulo (Hospital das Clínicas).

The specialists were instructed to fill out a questionnaire of 66 objective questions. The alternatives tried to identify the most frequent treatments on different stages of and gather information about local treatments, complications and adverse reactions during ambulatory follow-up.

\section{Economic analysis}

The studied population was a hypothetical cohort of men over 55 years with BPH treated in public health facilities. The drugs considered for the analyses were finasteride, doxazosine or combinations, based on randomized clinical trials (1013) and Brazilian health system reality (less costly).

The period of time analyzed of the base case scenario reflected the follow-up period of the clinical trials that evaluated the safety and efficacy of the above drugs. In the sensitivity analysis, this period of time was adapted to life time, since BPH is a chronic disease that demands long-term use of drugs, from the time of diagnosis until death.

Epidemiological data regarding incidence, prevalence and natural history of the disease were collected in international observational studies. The economic analysis considered the need of surgery and occurrence of AUR as outcomes. The risks of these events were obtained in clinical trials during the systematic review of literature.
Some data obtained in the specialist panel were used in the economic model. In that case, the information were submitted to sensitivity analysis. The annual mortality rate used was obtained from the last report of the Instituto Brasileiro de Geografia e Estatística (IBGE) (14).

Health resources included drugs, materials, laboratorial and image exams, surgeries and hospitalizations.

The costs of the were obtained from the Price Database of the Ministry of Health (15), which presented the mean price of the drugs bought by public hospitals, according to the quantity purchased.

The unitary costs of laboratorial and image exams, medical visits and physiotherapy were obtained using the software Sigtap Desktop ("Sistema de Gerenciamento da Tabela de Procedimentos, Medicamentos e OPM do SUS" - Management of Procedures and Drugs of SUS). The unitary costs of materials were obtained from the magazine SIMPRO. Prices were related to December 2010 (16). The current economic analysis included only the direct medical costs. For the estimation of costs and treatments, it was proposed a model that included the estimated number of AUR episodes and surgeries related to $\mathrm{BPH}$, according to the different stages of the disease and based on the Markov states (Figure-1). Microsoft Excel 2007 software was used to analyze the data.

\section{Figure 1: Health states considered in the Markov model.}

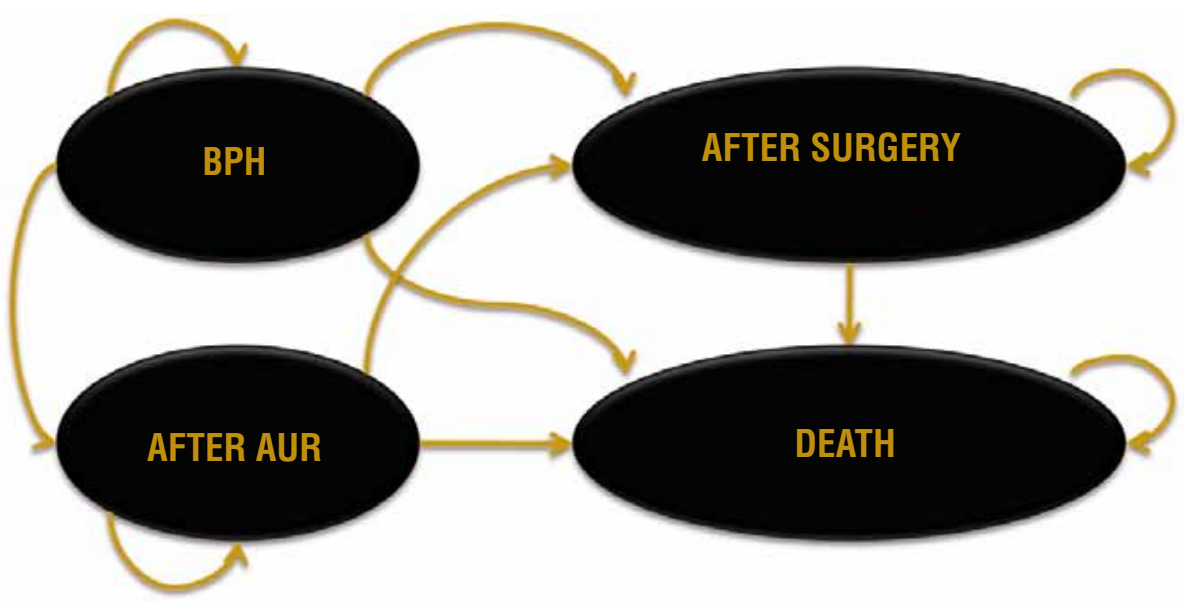


A discount rate of 5\% per year was applied in order to reflect the present cost, varying from $0 \%$ to $10 \%$. Sensitivity analysis was performed according to the recommendations of the Brazilian Ministry of Health (17). Brazilian currency was converted to American dollars according to the theory of Purchase parity Power (PPP 2010: US\$ $1=\mathrm{R} \$ 1.70$ ) (18).

\section{RESULTS}

\section{Cost-Effectiveness Analysis}

The data obtained from the panel showed that the most common drugs used in the treatment of BPH were finasteride, doxazosine and a combination of both. The most frequent surgery performed was transurethral resection of the prostate.

The comparative results of the available alternatives of treatment were determined by the incremental cost-effectiveness ratio (ICERs), defined as the additional cost of treatment divided by the additional gain in health obtained by two different alternatives of treatment.

This benefit was expressed in terms of AUR episodes and BPH-related surgeries avoided. Considering the following therapeutic options: monotherapy with finasteride X placebo (observation), finasteride + doxazosine $\mathrm{X}$ placebo and finasteride + doxazosine $X$ finasteride, the results of efficacy, costs and incremental cost-effectiveness rates are present in Tables 1,2 and 3, respectively.

\section{Sensitivity Analysis}

In order to further analyze the results of the treatment with finasteride compared to placebo, several parameters were evaluated in a univariate sensitivity analysis and are presented in Table-4.

Table 1 - Efficacy and incremental costs of finasteride treatment or placebo in a period of 6 years (per patient).

\begin{tabular}{lccc}
\hline & Finasteride & Placebo & Incremental \\
\hline Outcome & & & \\
Number of surgeries performed & 0.05 & 0.12 & 0.07 \\
Number of episodes of acute urinary retention & 0.03 & 0.07 & 0.04 \\
Costs & & & \\
Drug & & $\mathrm{R} \$ 0.00$ & $\mathrm{R} \$ 235.02$ \\
Follow-up ${ }^{2}$ & $\mathrm{R} \$ 235.02$ & $\mathrm{R} \$ 461.74$ & $\mathrm{R} \$ 17.83$ \\
Surgery & $\mathrm{R} \$ 479.57$ & $\mathrm{R} \$ 19.89$ & $-\mathrm{R} \$ 11.86$ \\
Acute urinary retention & $\mathrm{R} \$ 8.03$ & $\mathrm{R} \$ 88.55$ & $-\mathrm{R} \$ 51.27$ \\
Follow-up after surgery & $\mathrm{R} \$ 37.28$ & $\mathrm{R} \$ 9.28$ & $-\mathrm{R} \$ 5.08$ \\
Infection after AUR & $\mathrm{R} \$ 4.21$ & $\mathrm{R} \$ 0.11$ & $-\mathrm{R} \$ 0.07$ \\
\hline Total & $\mathrm{R} \$ 0.04$ & $\mathrm{R} \$ 579.57$ & $\mathrm{R} \$ 184.57$ \\
\hline ICER & $\mathrm{R} \$ 764.11$ & & \\
ICER & $\mathrm{R} \$ 2.734,74$ (US\$1.608.67) per surgery avoided & & \\
\hline
\end{tabular}

${ }^{1}$ Cost only with finasteride;

${ }^{2}$ Cost of follow-up for patients using finasteride or without medical treatment (watchful waiting)

${ }^{*}$ AUR: acute urinary retention 
Table 2 - Efficacy and incremental costs with the combination of doxazosine + finasteride or placebo in a 4 year period (per patient).

\begin{tabular}{lccc}
\hline & Combination & Placebo & Incremental \\
\hline Outcome & & & \\
Number of surgeries performed & 0.01 & 0.04 & 0.03 \\
Number of episodes of acute urinary retention & 0.00 & 0.02 & 0.01 \\
Cost & & & \\
Drug & & $\mathrm{R} \$ 0.00$ & $\mathrm{R} \$ 232.43$ \\
Follow-up & \\
Surgery & $\mathrm{R} \$ 232.43$ & $\mathrm{R} \$ 114.55$ \\
Acute urinary retention & $\mathrm{R} \$ 425.79$ & $\mathrm{R} \$ 311.25$ & $-\mathrm{R} \$ 3.88$ \\
Follow-up after surgery & $\mathrm{R} \$ 1.25$ & $\mathrm{R} \$ 5.13$ & $-\mathrm{R} \$ 20.35$ \\
Infection after AUR & \\
\hline Total & $\mathrm{R} \$ 10.11$ & $\mathrm{R} \$ 30.46$ & $-\mathrm{R} \$ 1.80$ \\
\hline ICER & $\mathrm{R} \$ 0.92$ & $\mathrm{R} \$ 2.73$ & $-\mathrm{R} \$ 0.02$ \\
\hline ICER & $\mathrm{R} \$ 0.00$ & $\mathrm{R} \$ 0.02$ & $\mathrm{R} \$ 320.93$ \\
\hline
\end{tabular}

${ }^{1}$ Cost with doxazosine and finasteride only;

${ }^{2}$ Cost of follow-up of patients using doxazosine + finasteride or patients without treatment (watchful waiting)

${ }^{*}$ AUR: acute urinary retention

It was observed that the cost of finasteride, the surgery number and the rate of treatment discontinuity were the variables with greater impact in the results (Figure-2).

A probabilistic sensitivity analysis was also performed considering the variations of many parameters at a time, assigning an appropriate distribution of each parameter previously described in Table-4. This analysis was calculated using 1,000 simulations and the results are shown in Figure 3 (A and B).

In a period of 6 years, one patient using finasteride had an additional cost of $\mathrm{R} \$ 184.50$ (CI 95\% R $\$ 135.83$ - $\mathrm{R} \$ 232.32$ ), a decrease of surgeries of 0.0672 (CI 95\% $0.0482-0.0862$ ) and a decrease of the AUR episodes of 0.0443 (CI05\% $0.0286-0.0583$ ).

\section{DISCUSSION}

Prospective studies demonstrate a relationship between the incidence of symptomatic BPH and aging (4), black race, inherited factors and obesity (19). Although the Brazilian incidence of BPH is unknown, the population is getting older, has a significant percentage of black people and the incidence of obesity resembles the incidence in developed countries, (14).

These factors may anticipate an increase of men that will need treatment of BPH in years to come. Besides, most Brazilian population depends exclusively on the Public Health System (SUS) for their treatments.

According to obtained data from the panel of specialists, a public patient has limit access to 
Table 3 - Efficacy and incremental costs with the combination of doxazosine + finasteride and monotherapy with finasteride in a 4 year period (per patient).

\begin{tabular}{|c|c|c|c|}
\hline & Combination & Finasteride & Incremental \\
\hline \multicolumn{4}{|l|}{ Outcome } \\
\hline Number of surgeries performed & 0.01 & 0.02 & 0.003 \\
\hline Number of episodes of acute urinary retention & 0.00 & 0.01 & 0.002 \\
\hline \multicolumn{4}{|l|}{ Cost } \\
\hline Drug ${ }^{1}$ & $\mathrm{R} \$ 232.43$ & $\mathrm{R} \$ 178.70$ & $\mathrm{R} \$ 53.73$ \\
\hline Follow-up ${ }^{2}$ & $\mathrm{R} \$ 425.79$ & $\mathrm{R} \$ 364.65$ & $\mathrm{R} \$ 61.15$ \\
\hline Surgery & $\mathrm{R} \$ 1.25$ & $\mathrm{R} \$ 1.83$ & $-R \$ 0.59$ \\
\hline Acute urinary retention & $\mathrm{R} \$ 10.11$ & $\mathrm{R} \$ 12.05$ & $-R \$ 1.94$ \\
\hline Follow-up after surgery & $\mathrm{R} \$ 0.92$ & $\mathrm{R} \$ 1.11$ & $-R \$ 0.19$ \\
\hline Infection after AUR ${ }^{\star}$ & $\mathrm{R} \$ 0.00$ & $\mathrm{R} \$ 0.01$ & $\mathrm{R} \$ 0.00$ \\
\hline Total & $\mathrm{R} \$ 670.50$ & $\mathrm{R} \$ 558.34$ & $\mathrm{R} \$ 112.16$ \\
\hline ICER & \multicolumn{3}{|c|}{$\mathrm{R} \$ 43.947,88$ (US\$ 25.851,69) per surgery avoided } \\
\hline ICER & \multicolumn{3}{|c|}{$\mathrm{R} \$ 50.764,83$ (US\$ 29.861.66) per AUR episode avoided } \\
\hline
\end{tabular}

${ }^{1}$ Cost with doxazosine and finasteride only

${ }^{2}$ Cost of follow-up of patients using doxazosine+finasteride or patients with monotherapy with finasteride

*AUR: acute urinary retention

drugs treatment and the percentage of long-term adherence to treatment is low $(30 \%$ of patients discontinue treatment after 1 year). Costs and adverse reactions, especially sexual complaints, are the main reasons for treatment discontinuation. On the other hand, the panel revealed that when a prostatic surgery is indicated, the patients wait a median of six months for it even with the use of a bladder catheter. These data were obtained in two major Brazilian medical centers probably nationally this reality is still more dramatic.

Although several aspects of physiopathology of BPH are still unknown, many important achievements were observed in the last decades and some risk factors for the worsening of symptoms and AUR were identified through longitudinal studies, as age, prostatic volume, pres- ence of more severe symptoms and higher PSA values $(20,21)$.

Finasteride diminishes significantly symptoms, the occurrence of AUR episodes and the need of surgery (22). Although there is a stigma about the impact on sexual health, the percentage of these side effects is low (22).

Dutasteride, a more recent 5-alpha-reductase inhibitor, shows comparable efficacy and tolerability (12), although with higher cost. On the other hand, doxazosine (11) and other alphablockers are efficient to reduce symptoms (23), delay the need of surgery $(24,25)$ without avoiding AUR episodes or surgery (26). The combined treatment with alpha-blockers and 5-alpha-reductase inhibitors is more efficient than monotherapy in patients with bigger prostates $(11,12)$. 
Table 4 - Different parameters of sensitivity analysis (finasteride or placebo in a 6 year period).

\begin{tabular}{|c|c|c|c|}
\hline Parameters & Base Case & Inferior limit & Superior limit \\
\hline Discount (outcome and cost) & $5.0 \%$ & $0 \%$ & $10 \%$ \\
\hline Finasteride cost - 5mg & $\mathrm{R} \$ 0.16$ & $\mathrm{R} \$ 0.08$ & $\mathrm{R} \$ 0.25$ \\
\hline Cost of episode of AUR & $\mathrm{R} \$ 265.49$ & $\mathrm{R} \$ 132.74$ & $\mathrm{R} \$ 398.23$ \\
\hline Cost of infection after AUR: first year after AUR & $\mathrm{R} \$ 0.24$ & $\mathrm{R} \$ 0.12$ & $\mathrm{R} \$ 0.36$ \\
\hline Cost of infection after AUR: following years & $\mathrm{R} \$ 0.36$ & $\mathrm{R} \$ 0.18$ & $\mathrm{R} \$ 0.54$ \\
\hline Cost of surgery & $\mathrm{R} \$ 759.58$ & $\mathrm{R} \$ 379.79$ & $\mathrm{R} \$ 1.139 .36$ \\
\hline Cost of follow-up after surgery & $\mathrm{R} \$ 96.48$ & $\mathrm{R} \$ 48.24$ & $\mathrm{R} \$ 144.72$ \\
\hline Placebo: Incidence of AUR ${ }^{\star}$ - First year 1 & $2.40 \%$ & $1.20 \%$ & $3.60 \%$ \\
\hline Placebo: Incidence of AUR - Year 2 & $1.86 \%$ & $0.93 \%$ & $2.79 \%$ \\
\hline Placebo: Incidence of AUR - Year 3 & $1.42 \%$ & $0.71 \%$ & $2.13 \%$ \\
\hline Placebo: Incidence of AUR - year 4 & $1.32 \%$ & $0.66 \%$ & $1.98 \%$ \\
\hline Finasteride: Incidence of AUR - year 1 & $0.99 \%$ & $0.50 \%$ & $1.49 \%$ \\
\hline Finasteride: Incidence of AUR: year 2 & $0.74 \%$ & $0.37 \%$ & $1.11 \%$ \\
\hline Finasteride: Incidence of AUR: year 3 & $0.48 \%$ & $0.24 \%$ & $0.72 \%$ \\
\hline Finasteride: Incidence of AUR: year 4 & $0.70 \%$ & $0.35 \%$ & $1.05 \%$ \\
\hline Finasteride: Incidence of AUR: year 5 & $0.08 \%$ & $0.04 \%$ & $0.12 \%$ \\
\hline Finasteride: Incidence of AUR: year 6 & $0.55 \%$ & $0.28 \%$ & $0.83 \%$ \\
\hline Placebo: Incidence of Surgery: Year 1 & $2.46 \%$ & $1.23 \%$ & $3.69 \%$ \\
\hline Placebo: Incidence of Surgery: year 2 & $3.58 \%$ & $1.79 \%$ & $5.37 \%$ \\
\hline Placebo: Incidence of Surgery: Year 3 & $2.32 \%$ & $1.16 \%$ & $3.48 \%$ \\
\hline Placebo: Incidence of Surgery: year 4 & $2.35 \%$ & $1.18 \%$ & $3.53 \%$ \\
\hline Finasteride: Incidence of Surgery : year 1 & $1.19 \%$ & $0.60 \%$ & $1.79 \%$ \\
\hline Finasteride: Incidence of Surgery: year 2 & $1.48 \%$ & $0.74 \%$ & $2.22 \%$ \\
\hline Finasteride: Incidence of Surgery: year 3 & $0.62 \%$ & $0.31 \%$ & $0.93 \%$ \\
\hline Finasteride: Incidence of Surgery: year 4 & $1.49 \%$ & $0.75 \%$ & $2.24 \%$ \\
\hline Finasteride: Incidence of Surgery: Year 5 & $0.40 \%$ & $0.20 \%$ & $0.60 \%$ \\
\hline Finasteride: Incidence of Surgery: Year 6 & $1.02 \%$ & $0.51 \%$ & $1.53 \%$ \\
\hline Percentage of Discontinuity of Finasteride (in 4 years) & $34.00 \%$ & $17.00 \%$ & $51.00 \%$ \\
\hline
\end{tabular}

*AUR: Acute urinary retention 
Figure 2 - Tornado graph (finasteride or placebo in a 6 year period).

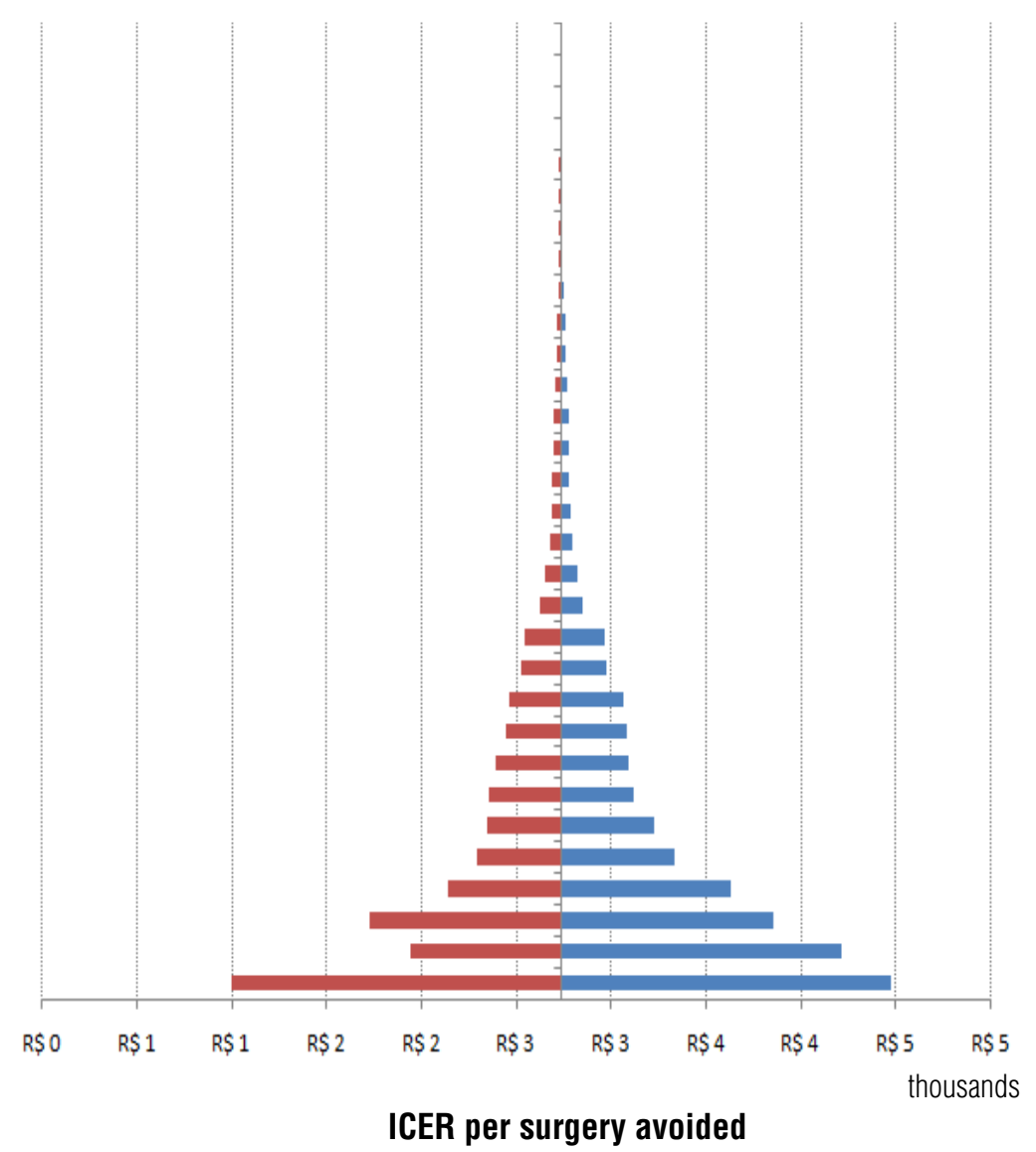

Cost of infection after AUR: first year after AUR

Cost of infection after AUR: following years

Finasteride: incidence of AUR: year 5

Finasteride: incidence of AUR: year 6

Finasteride: incidence of AUR: year 3

Finasteride: incidence of AUR: year 4

Finasteride: incidence of AUR: year 2

Finasteride: incidence of AUR: year 1

Placebo: incidence of AUR: year 3

Placebo: incidence of AUR: year 2

Cost of follow-up after surgery

Placebo: incidence of AUR: year 1

Placebo: incidence of AUR: year 4

Finasteride: incidence of surgery : year 5

Finasteride: incidence of surgery : year 6

Cost of episode of AUR

Finasteride: incidence of surgery : year 3

Rate of discount (outcome)

Finasteride: incidence of surgery : year 4

Finasteride: incidence of surgery : year 1

Finasteride: incidence of surgery : year 2

Rate of discount (outcome)

Cost of surgery

Placebo: incidence of surgery : year 3

Placebo: incidence of surgery : year 1

Placebo: incidence of surgery : year 2

Rate of discontinuity of finasteride

Placebo: incidence of surgery : year 4

Cost of finasteride: $5 \mathrm{mg}$
More recent data suggest that the continuous use of inhibitors of 5-alpha-reductase may lower the incidence of prostate cancer $(27,28)$. A possible increase of more aggressive tumors demands more studies of the capacity of finasteride to prevent prostate cancer (29).

Our study, based on the literature evidence and according to the Brazilian reality, concluded that monotherapy with finasteride for men with $\mathrm{BPH}$ over 55 years is a cost-effective therapeutic option. The combination of finasteride and doxazosine, although controlling more rapidly the lower urinary tract symptoms, increases significantly the cost of the treatment and the ICER of outcomes avoided.

According to the World Health Organization (30), a treatment can be considerate cost-effective if the treatment costs are equivalent to 3 times the gross national product (GNP) per capta (31) (Brazilian GNP/per capta: R\$ 19.016 / US\$ 11.186).

In view of these facts, the availability of finasteride at public health units, combined with identification of high risk patients would allow an efficient reduction of morbidity associated to $\mathrm{BPH}$, with great impact on quality of life.

This study has several limitations; the decision model analysis was based on efficacy data of randomized clinical trials, not corrected to real world (effectiveness) or to Brazilian people. This was due to the lack of validated methods to correct this distortion and absence of national data. This was one of the reasons why a panel of specialists was performed, that in turn had a limited number of specialists representing only two Brazilian states (southeast region). In order to minimize the impact 
Figures 3 A and 3 B): Results of the sensitivity analysis of ICER per surgery (A) and AUR (B) avoided (finasteride or placebo in a 6 year period). The results were evaluated and classified in: Quadrant 1 (incremental efficacy $>0$ and incremental cost $>0$ ): Quadrant 2 (incremental efficacy $<0$ and incremental cost $<0$ ); Quadrant 3 (incremental efficacy $<0$ and incremental cost $<0$ ); Quadrant 4 (incremental efficacy $>0$ and incremental cost $>0$ ). For this analysis, it was considered a cohort of 100 patients.
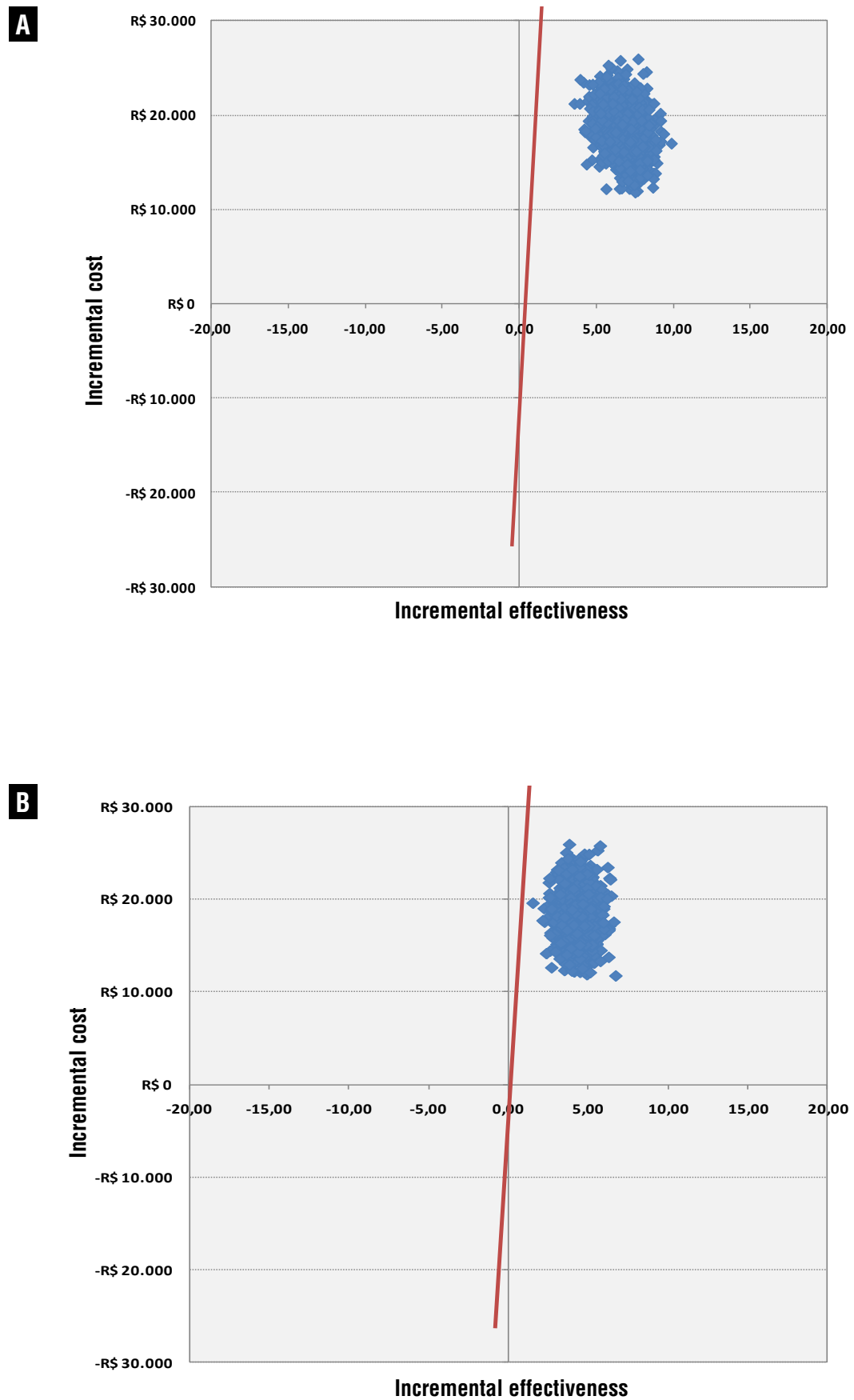
of this limitation on the results, all data were incorporated into a sensitivity analysis. An extrapolation of the analysis for a longer period of time (lifetime was done; however, it is known that this extrapolation lowers the precision of the analysis. Still, the evolution of medical knowledge changes over time and offers new therapeutic and preventive options not considered initially in the model.

Also, it was not possible to determine the costs of the adverse events, the indirect costs and those related to quality of life. We considered these data very important and we figured a balance between the impact of side effects on the adherence and the benefits of the lowering of the symptoms with the use of the drug. New studies in this field will be very relevant and important for the decision-making process.

\section{CONCLUSIONS}

This study suggests that the treatment of $\mathrm{BPH}$ with finasteride is cost-effective compared to placebo in the scenario of the Brazilian public health system. Combined therapy (doxazosine + finasteride), although lowering more efficiently and rapidly lower urinary tract symptoms, increases significantly the treatment costs.

\section{CONFLICT OF INTEREST}

None declared.

\section{Financial support}

CNPq - National Counsel of Technological and Scientific Development

IATS - Institute of Technology Assessment

Health

\section{REFERENCES}

1. Garraway WM, Collins GN, Lee RJ: High prevalence of benign prostatic hypertrophy in the community. Lancet. 1991; 338: 469-71.

2. Jacobsen SJ, Girman CJ, Guess HA, Oesterling JE, Lieber MM: New diagnostic and treatment guidelines for benign prostatic hyperplasia. Potential impact in the United States. Arch Intern Med. 1995; 155: 477-81.
3. Boyle P, Robertson C, Mazzetta C, Keech M, Hobbs FD, Fourcade $\mathrm{R}$, et al.: The prevalence of lower urinary tract symptoms in men and women in four centres. The UrEpik study. BJU Int. 2003; 92: 409-14.

4. Verhamme KM, Dieleman JP, Bleumink GS, van der Lei J, Sturkenboom MC, Artibani W, et al.: Incidence and prevalence of lower urinary tract symptoms suggestive of benign prostatic hyperplasia in primary care--the Triumph project. Eur Urol. 2002; 42: 323-8.

5. Clifford GM, Logie J, Farmer RD: How do symptoms indicative of $\mathrm{BPH}$ progress in real life practice? The UK experience. Eur Urol. 2000; 38(Suppl 1): 48-53.

6. Logie JW, Clifford GM, Farmer RD, Meesen BP: Lower urinary tract symptoms suggestive of benign prostatic obstruction-Triumph: the role of general practice databases. Eur Urol. 2001; 39(Suppl 3): 42-7.

7. Wagrell L, Schelin S, Nordling J, Richthoff J, Magnusson B, Schain M, et al.: Feedback microwave thermotherapy versus TURP for clinical BPH--a randomized controlled multicenter study. Urology. 2002; 60: 292-9.

8. Jacobsen SJ, Jacobson DJ, Girman CJ, Roberts RO, Rhodes T, Guess HA, et al.: Natural history of prostatism: risk factors for acute urinary retention. J Urol. 1997; 158: 481-7.

9. AUA Practice Guidelines Committee: AUA guideline on management of benign prostatic hyperplasia (2003). Chapter 1: Diagnosis and treatment recommendations. J Urol. 2003; 170(2 Pt 1): 530-47.

10. McConnell JD, Bruskewitz R, Walsh P, Andriole G, Lieber M, Holtgrewe HL, et al.: The effect of finasteride on the risk of acute urinary retention and the need for surgical treatment among men with benign prostatic hyperplasia. Finasteride Long-Term Efficacy and Safety Study Group. N Engl J Med. 1998; 338: 557-63.

11. McConnell JD, Roehrborn CG, Bautista OM, Andriole GL Jr, Dixon CM, Kusek JW, et al.: The long-term effect of doxazosin, finasteride, and combination therapy on the clinical progression of benign prostatic hyperplasia. N Engl J Med. 2003; 349: 2387-98.

12. Roehrborn CG, Siami P, Barkin J, Damião R, Major-Walker $\mathrm{K}$, Nandy I, et al.: The effects of combination therapy with dutasteride and tamsulosin on clinical outcomes in men with symptomatic benign prostatic hyperplasia: 4-year results from the CombAT study. Eur Urol. 2010; 57: 123-31. Erratum in: Eur Urol. 2010; 58: 801.

13. Kaplan S, Garvin D, Gilhooly P, Koppel M, Labasky R, Milsten $\mathrm{R}$, et al:: Impact of baseline symptom severity on future risk of benign prostatic hyperplasia-related outcomes and longterm response to finasteride. The Pless Study Group. Urology. 2000; 56: 610-6.

14. Tsukamoto $T$, Endo $\mathrm{Y}$, Narita M: Efficacy and safety of dutasteride in Japanese men with benign prostatic hyperplasia. Int J Urol. 2009; 16: 745-50. 
15. Debruyne FM, Jardin A, Colloi D, Resel L, Witjes WP, Delauche-Cavallier MC, et al.: Sustained-release alfuzosin, finasteride and the combination of both in the treatment of benign prostatic hyperplasia. European ALFIN Study Group. Eur Urol. 1998; 34: 169-75.

16. Kaplan SA, McConnell JD, Roehrborn CG, Meehan AG, Lee MW, Noble WR, et al.: Combination therapy with doxazosin and finasteride for benign prostatic hyperplasia in patients with lower urinary tract symptoms and a baseline total prostate volume of $25 \mathrm{~mL}$ or greater. J Urol. 2006; 175: 217-20; discussion 220-1.

17. Ministério da Saúde / Secretaria de Ciência TelEDdCeT. Diretrizes Metodológicas. Estudos de Avaliação Econômica de Tecnologias em Saúde. Série A. Normas e Manuais Técnicos. 2009. [homepage in internet]. available at: http://bvsms. saude.gov.br/bvs/publicacoes/avaliacao_economica_tecnologias_saude_2009.pdf

18. Word bank: available at: http://data.worldbank.org/ accessed in: mar, 2012.

19. Kristal AR, Arnold KB, Schenk JM, Neuhouser ML, Weiss N, Goodman P, et al.: Race/ethnicity, obesity, health related behaviors and the risk of symptomatic benign prostatic hyperplasia: results from the prostate cancer prevention trial. J Urol. 2007; 177: 1395-400; quiz 1591.

20. Roehrborn CG: Acute urinary retention: risks and management. Rev Urol. 2005; 7(Suppl 4): S31-41.

21. Crawford ED, Wilson SS, McConnell JD, Slawin KM, Lieber MC, Smith JA, et al.: Baseline factors as predictors of clinical progression of benign prostatic hyperplasia in men treated with placebo. J Urol. 2006; 175: 1422-6; discussion 1426-7.

22. Tacklind J, Fink HA, Macdonald R, Rutks I, Wilt TJ: Finasteride for benign prostatic hyperplasia. Cochrane Database Syst Rev. 2010; 10: CD006015.

23. Kirby RS, Roehrborn C, Boyle P, Bartsch G, Jardin A, Cary $M M$, et al.: Efficacy and tolerability of doxazosin and finasteride, alone or in combination, in treatment of symptomatic benign prostatic hyperplasia: the Prospective European Doxazosin and Combination Therapy (PREDICT) trial. Urology. 2003; 61: 119-26.
24. Roehrborn CG: Alfuzosin $10 \mathrm{mg}$ once daily prevents overall clinical progression of benign prostatic hyperplasia but not acute urinary retention: results of a 2-year placebo-controlled study. BJU Int. 2006; 97: 734-41.

25. Lloyd SN, Buckley JF, Chilton CP, Ibrahim I, Kaisary AV, Kirk $\mathrm{D}$ : Terazosin in the treatment of benign prostatic hyperplasia: a multicentre, placebo-controlled trial. Br J Urol. 1992; 70(Suppl 1): 17-21.

26. Boyle P, Roehrborn C, Harkaway R, Logie J, de la Rosette J, Emberton M: 5-Alpha reductase inhibition provides superior benefits to alpha blockade by preventing AUR and BPHrelated surgery. Eur Urol. 2004; 45: 620-6; discussion 626-7.

27. Thompson IM, Goodman PJ, Tangen CM, Lucia MS, Miller GJ, Ford LG, et al:: The influence of finasteride on the development of prostate cancer. N Engl J Med. 2003 17; 349: 215-24.

28. Kaplan SA, Roehrborn CG, Meehan AG, Liu KS, Carides AD, Binkowitz BS, et al.: PCPT: Evidence that finasteride reduces risk of most frequently detected intermediate- and high-grade (Gleason score 6 and 7) cancer. Urology. 2009; 73: 935-9.

29. Lucia MS, Epstein JI, Goodman PJ, Darke AK, Reuter VE, Civantos $\mathrm{F}$, et al.: Finasteride and high-grade prostate cancer in the Prostate Cancer Prevention Trial. J Natl Cancer Inst. 2007; 99: 1375-83.

30. Organização Mundial de Saúde (OMS). [homepage in internet]. available at: http://www.who.int/choice/costs/CER thresholds/en/index.html. [accessed in mar, 2012].

31. Instituto Brasileiro de Geografia E Estatística (IBGE). Produto Interno Bruto (PIB). [homepage in internet]. available at: http://www.ibge.gov.br/home/presidencia/noticias/noticia_ visualiza.php?id_noticia=1830\&id_pagina=1]. [accessed in mar, 2012].

Correspondence address: Dr. Valter Javaroni State University of Rio de Janeiro R. São Francisco Xavier, 524 - Maracanã Rio de Janeiro, RJ, 20550-013, Brazil Email:drjavaroni2000@yahoo.com.br 